\title{
Population dynamics, relative growth and sex change of the protandric simultaneous hermaphrodite Exhippolysmata oplophoroides (Caridea: Lysmatidae) close to an upwelling area
}

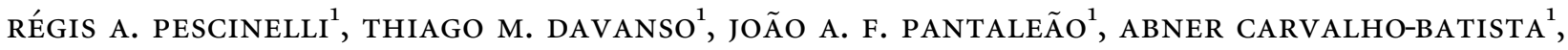 \\ RAYMOND T. BAUER ${ }^{2}$ AND ROGÉRIO C. COSTA ${ }^{1}$ \\ ${ }^{1}$ Laboratory of Biology of Marine and Freshwater Shrimp (LABCAM), Department of Biological Sciences, School of Sciences, \\ University of Sao Paulo State (UNESP), Av. Eng. Luiz Edmundo Corrijo Coube, 14-01, 17033-36o Bauru, SP, Brasil, ${ }^{2}$ Department of \\ Biology, University of Louisiana at Lafayette, Lafayette, Louisiana 70504-2451, USA
}

\begin{abstract}
The present study investigated the population dynamics of Exhippolysmata oplophoroides in an area influenced by upwelling, focusing on reproductive period, sex ratio, growth rate, longevity, mortality, relative growth and size of sex change. We also tested the hypothesis that the appendices internae increased in size with sex change from the male to the simultaneous hermaphrodite phase as possible replacements for the male appendices masculinae, which are reduced or lost at sex change. Population structure was assessed by the distribution of size frequency in three demographic groups: male phase, hermaphrodite phase with, and without embryos. For relative growth analysis, the length of the following structures was measured: carapace, second pleuron, first pereopod, second pereopod, appendices internae of the second to fifth pleopods, and appendix masculina. Smaller size classes were composed only by male-phase individuals. The sex ratio was significantly biased towards the simultaneous hermaphrodite phase. Reproduction was continuous in the population throughout the year. Slower growth rates but higher maximum body sizes than those estimated at other locations in south-eastern Brazil were observed in the population studied. Cooler temperatures and higher nutrient levels associated with upwelling may have produced this pattern of reproduction and growth, similar to that found in more southerly austral latitudes. We also found that sex change influences the relative growth of body structures such as the second pereopods, appendices internae, and appendix masculina, and hypotheses on the adaptive value of such allometric growth are proposed.
\end{abstract}

Keywords: allometry, growth, reproduction, sex allocation, sex ratio, upwelling

Submitted 27 April 2016; accepted 12 December 2016; first published online 16 January 2017

\section{INTRDDUCTION}

Most decapod crustaceans have separate sexes (gonochorism), but some caridean species exhibit sequential hermaphroditism in which there is sexual reversal at a certain life stage (Bauer, 2000). When the individual first develops as a male and then later changes to a female, the sexual system is termed protandry or protandric hermaphroditism (PH). For a small group of Caridea, an even more specific type of hermaphroditism is described, i.e. protandric simultaneous hermaphroditism (PSH, Bauer, 2000). In this sexual system, the individual develops and reproduces initially as a male but subsequently changes sex into a functional simultaneous hermaphrodite. These latter individuals (female phase or FP in Bauer \& Holt, 1998; Bauer, 2000) have a primarily female phenotype,

Corresponding author:

R.C. Costa

Email: rccosta@fc.unesp.br produce and incubate embryos, but they can also mate successfully as males. During sex change, male secondary sexual characters such as the appendix masculina, a typical feature of caridean males associated with spermatophore transfer (Bauer, 1976; Berg \& Sandifer, 1984), are reduced or lost. Female external characters associated with spawning and the incubation of embryos are developed, but the gonads are functional ovotestes (Bauer \& Holt, 1998; Bauer, 2006; Baeza, 2009). This sexual pattern has been confirmed for all species of the genera Lysmata Risso, 1816 and Exhippolysmata Stebbing, 1915 and also for Parhippolyte misticia (Clark, 1989) (Laubenheimer \& Rhyne, 2008; Baeza, 2009; Braga et al., 2009; Onaga et al., 2012).

The spiny shrimp Exhippolysmata oplophoroides (Holthuis, 1948 ) is part of the by-catch taken in penaeid shrimp fisheries of high economic interest in Brazil (e.g. Xiphopenaeus kroyeri (Heller, 1862) and Litopenaeus schmitti (Burkenroad, 1936)) (Costa et al., 2000). Significant studies on E. oplophoroides include the Chacur \& Negreiros-Fransozo (1998) study on fecundity; the Negreiros-Fransozo et al. (2002) description 
of its first larval stage; the Fransozo et al. (2005) paper on population biology focusing on temporal distribution, size and reproductive period; Braga et al. (2009) and Laubenheimer \& Rhyne (2008) demonstrated PSH in this species; and Baeza et al. (2010) studied some aspects of population biology such as sex ratio age, mortality and reproductive period.

In this study, an E. oplophoroides population is studied for the first time near an upwelling area in which, despite its location at a tropical latitude $\left(22^{\circ} 33^{\prime} \mathrm{S}\right)$, the shallow bottom water temperature does not exceed $21^{\circ} \mathrm{C}$ during most of the year (Silva et al., 2014; Pantaleão et al., 2016). In this area, the South Atlantic Central Water (SACW) promotes nutrient transport $(\mathrm{N}$ and $\mathrm{P})$ from the bottom to the photic zone, directly influencing primary productivity (Odebrecht \& Djurfeldt, 1996). This increased primary productivity can have a great influence on both zooplankton and benthic communities (Mann \& Lazier, 1996). The concentration of chlorophyll- $a$ in the water column may reach values 10 times higher than those in the Ubatuba region (De Léo \& Pires-Vanin, 2006), where all previous studies on E. oplophoroides have been performed.

The energy allocation for physiological processes such as growth and reproduction is an important aspect of an animal's life history (Schaffer, 1983; Lika, 2003). The allocation of resources for reproductive processes in the male or female is defined as sex allocation, and it may influence the population structure, affecting for example the sex ratio (Charnov, 1982). In PH and PSH species, the sex ratio can be biased toward the male or female $(\mathrm{PH})$ or simultaneous hermaphrodite phase (PSH) according to resource availability (Charnov, 1982; Baeza, 2007a). The estimate of the size at which the sex change occurs and the conditions affecting this change are applications of sex allocation theory in the life history of an organism (Charnov, 1982; Hardy, 2002).

Considering the abiotic and oceanographic features of upwelling areas and the influence of these characteristics on populations, the present study aimed to analyse the population dynamics of $E$. oplophoroides, testing the hypothesis that upwelling has a significant effect, in comparison to nonupwelling areas, on reproductive period, sex ratio, growth rate, longevity, mortality, relative growth and the size at which the sex phase change occurs. Given the results of Zhang \& Lin (2004) on the role of pleopod appendices in copulatory abilities of PSH individuals, we also tested the hypothesis that growth of the appendices internae of the pleopods changed with sex change from the male to the simultaneous hermaphrodite phase.

\section{MATERIALS AND METHODS}

\section{Sampling}

Shrimps were collected monthly from July 2010 to June 2011 on the northern coast of Rio de Janeiro (Macaé - RJ, $22^{\circ} 33^{\prime} \mathrm{S}$ $41^{\circ} 78^{\prime} \mathrm{W}$ ). Six locations were sampled: 3 at $5 \mathrm{~m}, 3$ at $15 \mathrm{~m}$. Sampling was done using a shrimp boat equipped with 10-metre-long double-rig shrimp trawls, with $20 \mathrm{~mm}$ net mesh and $18 \mathrm{~mm}$ cod-end mesh. Each location was trawled over a $30 \mathrm{~min}$ period at a constant speed of 2.0 knots, and $\sim 18,500 \mathrm{~m}^{2}$ were covered in each trawl sample. After sampling, shrimps were bagged, stored in coolers with crushed ice, taken to the laboratory and later preserved in $70 \%$ ethanol, after measurements and observations were taken.

The carapace length (CL) of individuals was measured with a digital caliper to $0.01 \mathrm{~mm}$. Individuals were classified as male or simultaneous hermaphrodite according to the developmental stage of the appendix masculina on the endopod of the second pleopod, i.e. well developed and with spines in the male phase and reduced and spineless in the hermaphrodite phase (Braga et al., 2009).

\section{Population dynamics}

The population structure was assessed by the distribution of size frequency in different demographic categories (MP: male phase; HP: hermaphrodite phase without embryos; and HP-E hermaphrodite phase with embryos), using size classes with $1 \mathrm{~mm}$ intervals.

The reproductive period was calculated based on the frequency of the hermaphrodite phase with embryos in each month sampled. For the sex ratio, we used the Chi squared test $\left(\chi^{2}\right)$ for goodness of fit $(\alpha=0.05)$ (Sokal \& Rohlf, 1995) to determine if the sex ratio was significant biased towards MPs or HPs throughout the study period.

\section{Growth, longevity and mortality}

Considering that E. oplophoroides is a protandric simultaneous hermaphrodite (PSH) species, the growth analysis was performed by grouping male and hermaphrodite phases. For each sample month, the length (CL) frequency was distributed in $1 \mathrm{~mm}$ size classes, and modes were calculated using the software 'PeakFit' (PeakFit v. 4.06 SPSS Inc. for Windows Copyright 1991-1999, AISN Software Inc.).

For estimates of growth parameters, all identified cohorts were adjusted to the growth model of Von Bertalanffy (1938): $\mathrm{CL}_{t}=\mathrm{CL}_{\infty}\left[1-e^{-k\left(t-t_{0}\right)}\right]$, where the carapace length $\mathrm{CL}_{t}$ is the estimated size at age $t, \mathrm{CL}_{\infty}$ is the asymptotic size, $\mathrm{k}$ is the growth coefficient and $t_{\mathrm{o}}$ is the theoretical point in time when the individual has zero length. Growth parameters were estimated for the different cohorts with the Excel tool 'Solver', varying the equation parameters $\mathrm{CL}_{\infty}, k$ and $t_{\mathrm{o}}$. The selected cohorts were those consistent with the species' life history cycle, considering longevity, the growth coefficient $k$ and asymptotic size $\left(\mathrm{CL}_{\infty}\right)$. Comparison of the growth curves was performed using an $F$ test $(P=0.05)$ (Cerrato, 1990 ). Longevity was estimated by the inverse equation of Von Bertalanffy, with modifications suggested by D'Incao \& Fonseca (1999), considering $t_{\mathrm{o}}=0$ and $\mathrm{CL} / \mathrm{CL}_{\infty}=0.99$. The longevity equation is given by: $t=\left(t_{\mathrm{o}}-(1 / k) \mathrm{Ln}\left(1-\mathrm{CL}_{t}\right)\right.$ $\mathrm{CL}_{\infty}$ ).

The empirical natural mortality (M) (Pauly, 1980) was calculated by the Beverton \& Holt (1959) method using the FISAT II program (Food and Agriculture Organization of the United Nations; http://www.fao.org/fishery/topic/16072/ en\#3).

\section{Relative growth and size estimate of the sex change}

For relative growth analyses, the following structures were measured in 407 individuals: AIL2-5 length of the appendix interna of the second to fifth pleopod; AML, length of 
appendix masculine; CL, carapace length; FPL, length of first pereopod; PL, length of second pleuron; SPL, length of second pleopod (Figure 1). The appendices internae link the endopods of each segmental pair of pleopods; the appendix masculina is a typical structure on the endopods of the second pleopods of caridean shrimp males (Bauer, 2004) which is thought to be involved in copulation and sperm transfer (Bauer, 2013).

The relative growth analysis allows for detecting possible changes in the growth pattern of body structures as a function of an independent variable (CL). The allometric equation $y=$ $a x^{b}$ was used in the linearized version $(\log y=\log a+b$ $\log x$ ), in which $y$ is the dependent variable (morphological structure), $x$ is the independent variable (CL), $b$ is the allometric coefficient and $a$ is where the line intersects the y-axis. The allometric condition $b$ for each structure was analysed $(b=1$ : isometry, $b<1$ : negative allometry, $b>1$ : positive allometry) with a Student's $t$-test $\left(H_{\mathrm{o}}: b=1 ; \alpha=0.05\right)$ (Zar, 1996). The angular and linear coefficients $a$ and $b$, respectively, from the male and hermaphrodite phases were subjected to an analysis of covariance (ANCOVA) test of homogeneity of slopes for each morphological structure in order to determine whether the MP and HP groups could be represented by separate linear equations.

To determine the size of sex change in the population, the transformed data $\left(\log _{10}\right)$ were subjected to the nonhierarchical analysis ' $K$-means clustering'. This method distributes data in groups of numbers previously established by an iterative process that minimizes variance inside groups and maximizes the variance among them. The classification result ( $K$-means) was refined by applying a discriminant analysis. The size of the smallest individual classified by the discriminant analysis as belonging to the hermaphrodite phase was used as an estimated value at which the sexual change occurs. This statistical methodology was based on Sampedro et al. (1999).

\section{RESULTS}

\section{Population dynamics}

A total of 2156 individuals were collected: 630 in the male phase (MP), 343 in the hermaphrodite phase without embryos (HP) and 1183 in the hermaphrodite phase with embryos (HP-E). The minimum and maximum sizes CL $(\mathrm{mm})$ were 3.80 to $12.10(7.98 \pm 2.12)$ in the MP, 7.60 to $18.82(9.97 \pm 1.99)$ in the HP and 6.70 at $20: 18(11: 49 \pm$ 1.98) in the HP-E.

The highest frequency of individuals in the MP were observed in the $8-9 \mathrm{~mm}$ size classes (CL), while individuals in the HP had higher proportions in the 10-11 $\mathrm{mm}$ size classes (CL) (Figure 2). Two peaks in the MP were observed, one in September and another in May. Shrimp in the HP-E were present in all sample months and almost entirely with percentage values above $50 \%$, indicating continuous reproduction throughout the year (Figure 3). There was a statistically significant difference in the sex ratio $(P<0.05)$ in favour of the hermaphrodite phase in almost all sample months, except for September 2010 (Table 1).

\section{Growth, longevity and mortality}

Five cohorts were determined for the population of E. oplophoroides sampled in Macaé/RJ. The estimated growth parameters were $k=0.00576 \mathrm{~mm} \mathrm{day}^{-1}$ (or $k=0.17 \mathrm{~mm} \mathrm{month}^{-1}$ ), $t_{\mathrm{o}}=-0.24, \mathrm{CC}=18.89 \mathrm{~mm}$. The maximum longevity was estimated to be 2.19 years (Figure 4 ) and the natural mortality was 0.07 month $^{-1}\left(M=0.856\right.$ year $\left.^{-1}\right)$.

\section{Relative growth and estimated size of sex change}

All relative growth equations for different morphological structures showed statistically significant differences between the male (MP) and hermaphrodite (HP) phases (ANCOVA $P<0.05$ ) (Table 2). The relationship which best represents the sex change was AML vs CL, showing a reduction in the male appendix after change from the MP to the HP (Figure 5). The estimate for the size of sex change is $9.93 \mathrm{~mm} \mathrm{CL}$.

The PL vs CL relationships indicated positive allometric growth in both phases. Growth was negatively allometric for the relationships FPL vs CL and AML vs CL. For the relationships SPL vs CL, AIL2 vs CL, AIL3 and AIL5 vs CL, negative allometric growth in the male phase was followed by positive allometric growth in the hermaphrodite phase. For the

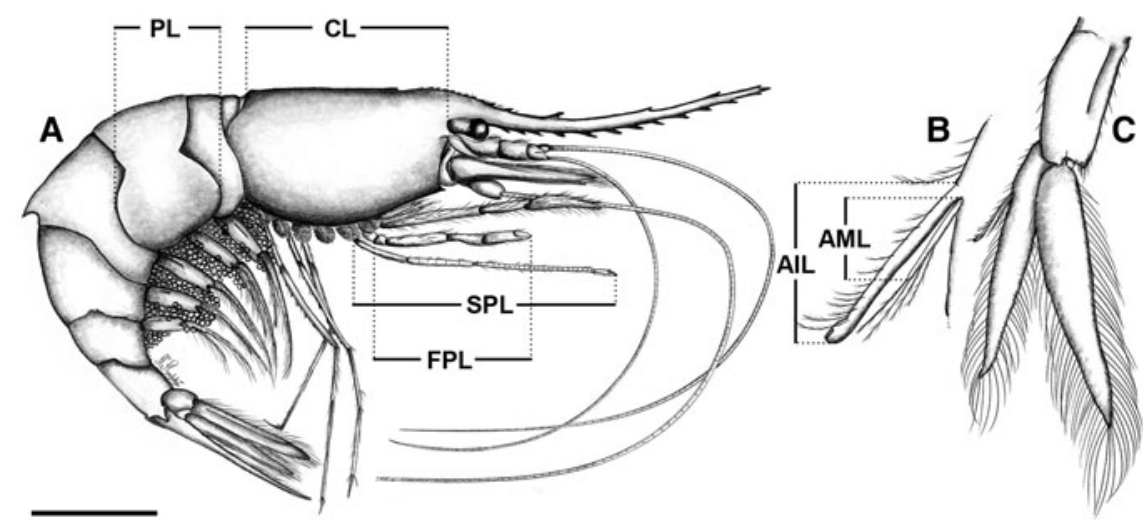

Fig. 1. Exhippolysmata oplophoroides (Holthuis, 1948). Body dimensions used in the morphometric analyses. (A) hermaphrodite carrying embryos, (B) magnification of appendix interna and masculina of the second pleopod, (C) second pleopod. AIL, length of appendix interna; AML, length of appendix masculine; CL, carapace length; FPL, length of first pereopod; PL, length of second pleuron; SPL, length of second pleopod. $(\mathrm{Scale}$ bar: $\mathrm{A}=10 \mathrm{~mm}$, $\mathrm{B}=$ $0.5 \mathrm{~mm}, \mathrm{C}=2 \mathrm{~mm}$ ) 


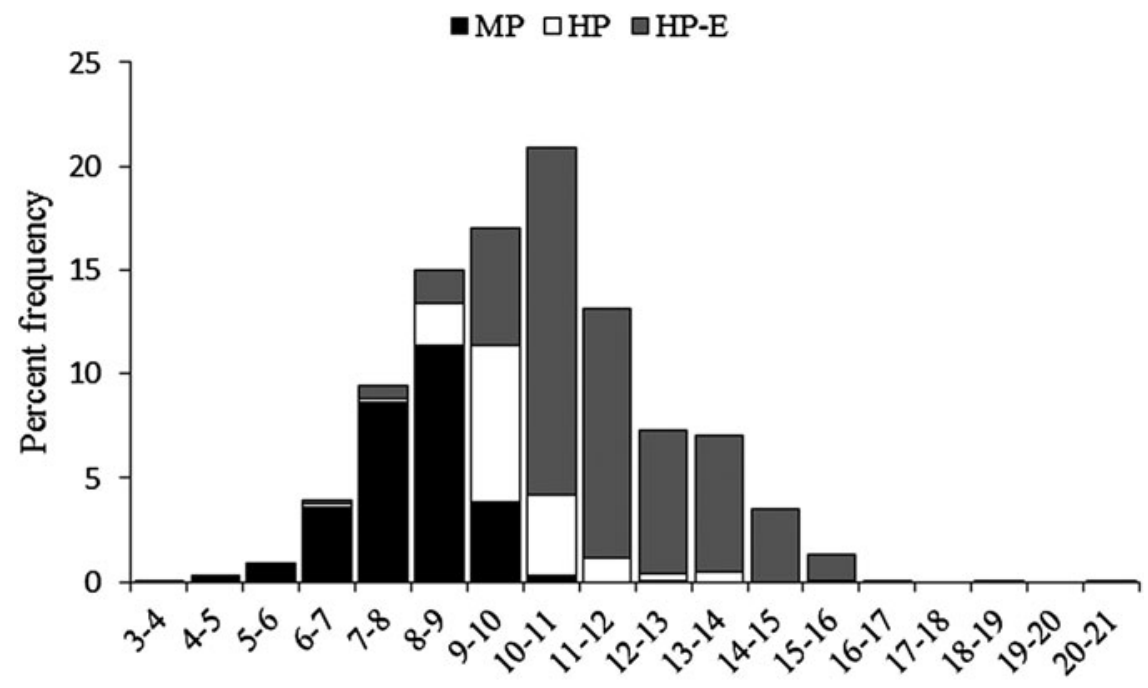

Carapace length (mm)

Fig. 2. Exhippolysmata oplophoroides (Holthuis, 1948). Size-frequency distribution of the male phase (MP) (black bars), hermaphrodite phase without embryos (HP) (white bars) and hermaphrodite phase with embryos (HP-E) (grey bars) (all individuals sampled: $\mathrm{N}=2156$ ).

relationship AIL4 vs CL, negative allometric growth was observed in the male phase followed by isometric growth. A detailed description of each relationship can be found in Table 3 .

\section{DISCUSSION}

The size distribution of the male phase (MP) and simultaneous hermaphroditic phase (HP) in E. oplophoroides, with a sex change from smaller MPs to larger HPs, is concordant with the size advantage model described by Ghiselin (1969) and Warner (1975), as well as sex allocation models (Baeza, 2007a). For Lysmata wurdemanni (Gibbes, 1850), another species with protandric simultaneous hermaphroditism (PSH), it was found that even the smallest male-phase individuals are able to copulate with larger hermaphrodites. The adaptive advantage of small male size in carideans is that they may be more cryptic and thus less vulnerable to predators, and have lower energy needs. These are advantages if males do not defend territory or compete agonistically for females, i.e. a 'pure search' (promiscuous) mating system (Wickler \& Seibt, 1981; Bauer, 2004). Lysmata wurdemanni (Bauer \& Holt, 1998; Bauer, 2006) and presumably E. oplophoroides (Laubenheimer \& Rhyne, 2008) have such a mating system. Female fecundity of the HPs in L. wurdemanni increases with increasing size (Bauer, 2005), as in other caridean shrimps (Bauer, 2004). We assume a similar relationship of size and sex allocation in E. oplophoroides.

A continuous reproductive period was observed, with hermaphrodite shrimp carrying embryos in all months sampled. In carideans with this type of reproduction, ovarian development usually occurs while embryos are incubating (Bauer, 2004). Thus, soon after larval hatching,

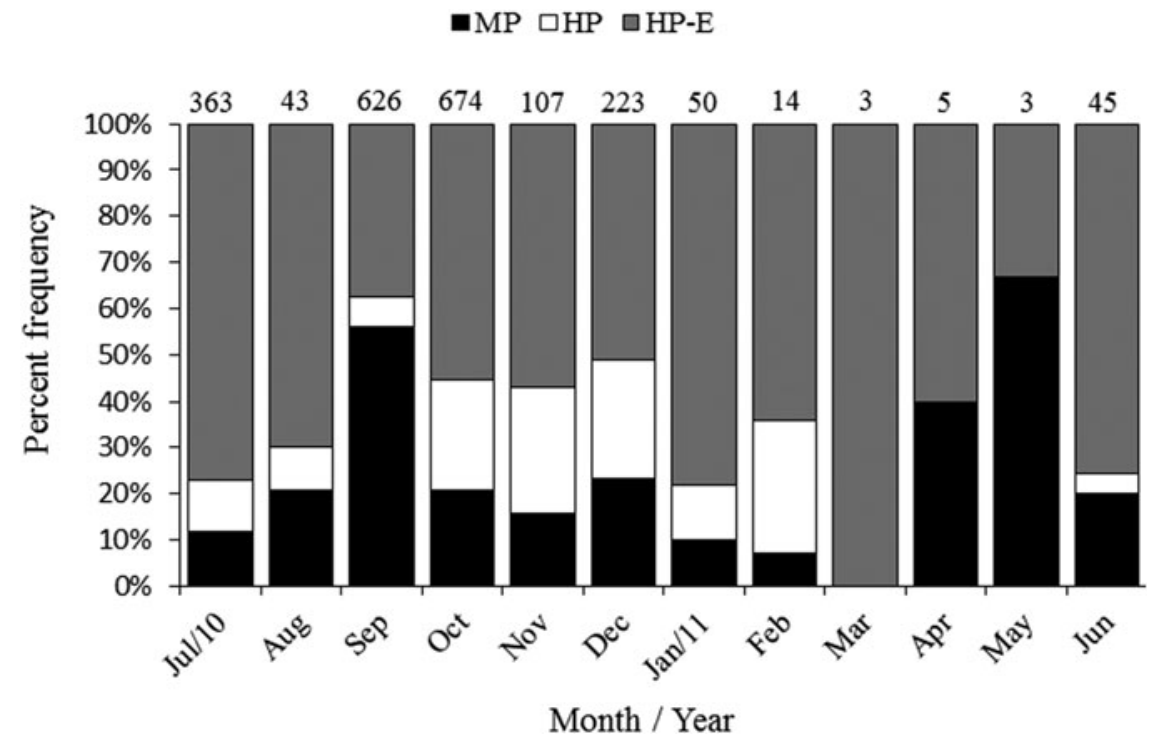

Fig. 3. Exhippolysmata oplophoroides (Holthuis, 1948). Monthly per cent frequency of the male phase (MP) (black bars), hermaphrodite phase without embryos (HP) (white bars) and hermaphrodite phase with embryos (HP-E) (grey bars). 
Table 1. Exhippolysmata oplophoroides (Holthuis, 1948).

\begin{tabular}{lrrrll}
\hline Month & MP & HP & \multicolumn{1}{c}{$\boldsymbol{\chi}^{2}$} & \multicolumn{1}{l}{$\boldsymbol{P}$-value } & MP/HP \\
\hline Jul-10 & 43 & 320 & 211.37 & $<0.0001^{*}$ & 0.12 \\
Aug-10 & 9 & 34 & 14.53 & $0.0001^{*}$ & 0.21 \\
Sep-10 & 350 & 276 & 8.74 & $0.0031^{*}$ & 0.56 \\
Oct-10 & 140 & 534 & 230.30 & $<0.0001^{*}$ & 0.21 \\
Nov-10 & 17 & 90 & 49.80 & $<0.0001^{*}$ & 0.16 \\
Dec-10 & 52 & 171 & 63.50 & $<0.0001^{*}$ & 0.23 \\
Jan-11 & 5 & 45 & 32.00 & $<0.0001^{*}$ & 0.10 \\
Feb-11 & 1 & 13 & - & - & - \\
Mar-11 & 0 & 3 & - & - & - \\
Apr-11 & 2 & 3 & - & - & - \\
May-11 & 2 & 1 & - & - & - \\
Jun-11 & 9 & 36 & 16.20 & $<0.0001^{*}$ & 0.20 \\
Total & 630 & 1526 & 372.36 & $<0.0001^{*}$ & 0.29 \\
\hline
\end{tabular}

Number of individuals in the male phase (MP) and number of individuals in the hermaphrodite phase (HP) from July 2010 to June 2011. The deviation from an equal sex ratio was tested for each month.

*Significant difference from $\mathrm{MP} / \mathrm{HP}=1$.o.

hermaphrodites of E. oplophoroides can copulate and produce a new brood of embryos. The ability of individuals in the hermaphrodite phase to reproduce as males or as females may also favour continuous reproduction.

Although the area of the present study has cooler waters than expected at the latitude studied due to upwelling (Silva et al., 2014; Pantaleão et al., 2016), the monthly frequency of hermaphrodites with embryos was usually above 50\%, similar to that found by Baeza et al. (2010) for the same species in the Ubatuba/SP region. Considering that this is a PSH species, in which smaller individuals (new recruits) are in the male phase, we can infer from our data that recruitment was also continuous, but with a peak in September.

The sex ratio was biased towards hermaphrodite phase in the present study, as found by Baeza et al. (2010) for E. oplophoroides in the Ubatuba/SP region. In the absence of mating opportunities, male-phase shrimps can accelerate their development and change to simultaneous hermaphrodites more quickly (Baeza \& Bauer, 2004), which may explain the dominance of the hermaphrodite phase. Thus, individuals increase their reproductive potential and can act as males or as females, according to the population structure and whether conditions favour behaving as a male or a female.

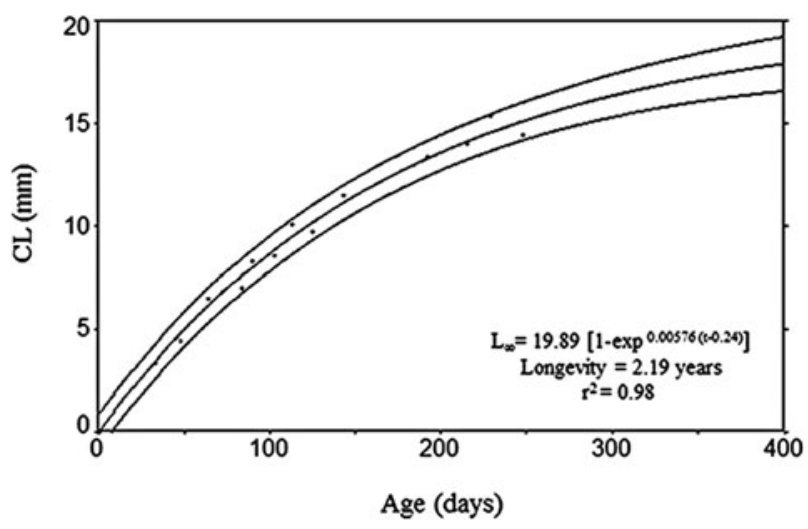

Fig. 4. Exhippolysmata oplophoroides (Holthuis, 1948). Growth curves estimated for the population of Macaé, Rio de Janeiro state. The middle line is the mean and the outer lines are the $95 \%$ confidence limits.
Table 2. Exhippolysmata oplophoroides (Holthuis, 1948).

\begin{tabular}{|c|c|c|c|c|}
\hline Relationship & Factor (group) & Par. (log) & $F$ & $P$ \\
\hline & & a & 11.795 & $0.000^{*}$ \\
\hline \multirow[t]{2}{*}{$\mathrm{PL} v s \mathrm{CL}$} & \multirow[t]{2}{*}{ MP vs HP } & $\mathrm{b}$ & 3.251 & 0.072 \\
\hline & & $\mathrm{a}$ & 14.664 & $0.000^{*}$ \\
\hline \multirow[t]{2}{*}{$\mathrm{FPL} v s \mathrm{CL}$} & \multirow[t]{2}{*}{ MP $v s \mathrm{HP}$} & b & 1.543 & 0.214 \\
\hline & & $\mathrm{a}$ & - & - \\
\hline \multirow[t]{2}{*}{ SPL $v s \mathrm{CL}$} & \multirow[t]{2}{*}{ MP $v s \mathrm{HP}$} & $\mathrm{b}$ & 14.143 & $0.000^{*}$ \\
\hline & & $\mathrm{a}$ & - & - \\
\hline \multirow[t]{2}{*}{ AIL2 vs CL } & \multirow[t]{2}{*}{$\mathrm{MP} v s \mathrm{HP}$} & $\mathrm{b}$ & 17.703 & $0.000^{*}$ \\
\hline & & $\mathrm{a}$ & - & - \\
\hline \multirow[t]{2}{*}{$\mathrm{AIL}_{3} v s \mathrm{CL}$} & \multirow[t]{2}{*}{$\mathrm{MP} v s \mathrm{HP}$} & $\mathrm{b}$ & 7.646 & $0.000^{*}$ \\
\hline & & a & - & - \\
\hline \multirow[t]{2}{*}{$\mathrm{AIL}_{4} v s \mathrm{CL}$} & \multirow[t]{2}{*}{$\mathrm{MP} v s \mathrm{HP}$} & $\mathrm{b}$ & 12.071 & $0.000^{*}$ \\
\hline & & a & - & - \\
\hline \multirow[t]{2}{*}{ AIL5 vs CL } & \multirow[t]{2}{*}{$\mathrm{MP} v s \mathrm{HP}$} & $\mathrm{b}$ & 10.307 & $0.001^{*}$ \\
\hline & & $\mathrm{a}$ & - & - \\
\hline $\mathrm{AML} v s \mathrm{CL}$ & MP $v s \mathrm{HP}$ & b & 38.314 & $0.000^{*}$ \\
\hline
\end{tabular}

Results of analysis of covariance (ANCOVA) tests for homogeneity of slopes to compare relative growth of possible secondary sexual characters between male and hermaphrodite phases.

AIL, length of appendix interna; AML, length of appendix masculine; CL, carapace length; FPL, length of first pereopod; PL, length of second pleuron; SPL, length of second pleopod; HP, simultaneous hermaphrodite phase; MP, Male phase.

Par $=$ parameter, $\mathrm{a}=$ intercept, $\mathrm{b}=$ slope,${ }^{*} P<0.05$.

However, in a study focusing on sex allocation in L. wurdemanni, initial males delayed their development when there was an increase in hermaphrodites in the population, which can reflect a response and/or phenotypic flexibility to environmental conditions (Baeza, 2007b). The results discussed above concerning the sex ratio reinforce the phenotypic plasticity of PSH species and their ability to change the sex ratio according to resource availability in the environment.

Concerning the maximum body size, $k$ and longevity of E. oplophoroides compared with that reported by Baeza et al. (2010), the greatest difference was with regard to age and lifespan. Longevity showed considerable differences ( $\sim_{2}$ years $)$ in two closely adjacent bays in the Ubatuba region (Table 4 ). This large difference in longevity in the Ubatuba population might be explained by variations in sediment characteristics and organic content, which could affect food availability and the presence or absence of predators. The values of $k$ and mortality might explain such differences, even though the techniques employed for such calculations were different in our study from that used in Baeza et al. (2010). There is a negative correlation between $k$ values and longevity. The physical features of the Macaé region, such as lower temperatures and higher primary productivity when compared with the Ubatuba region (De Léo \& Pires-Vanin, 2006), are probably the main factors that influenced larger sizes and constant growth. The natural mortality was also lower. In contrast, the mortality rate in Mar Virado Bay was very high (Table 4), although the $k$ and longevity values were similar in both regions.

As with the growth analyses, the estimated size at which the change from the male to the simultaneous hermaphrodite phase occurs showed higher values when compared with those found by Baeza et al. (2010) in Ubatuba. Possible physiological adaptations to different environmental conditions could explain these differences in maximum size, 


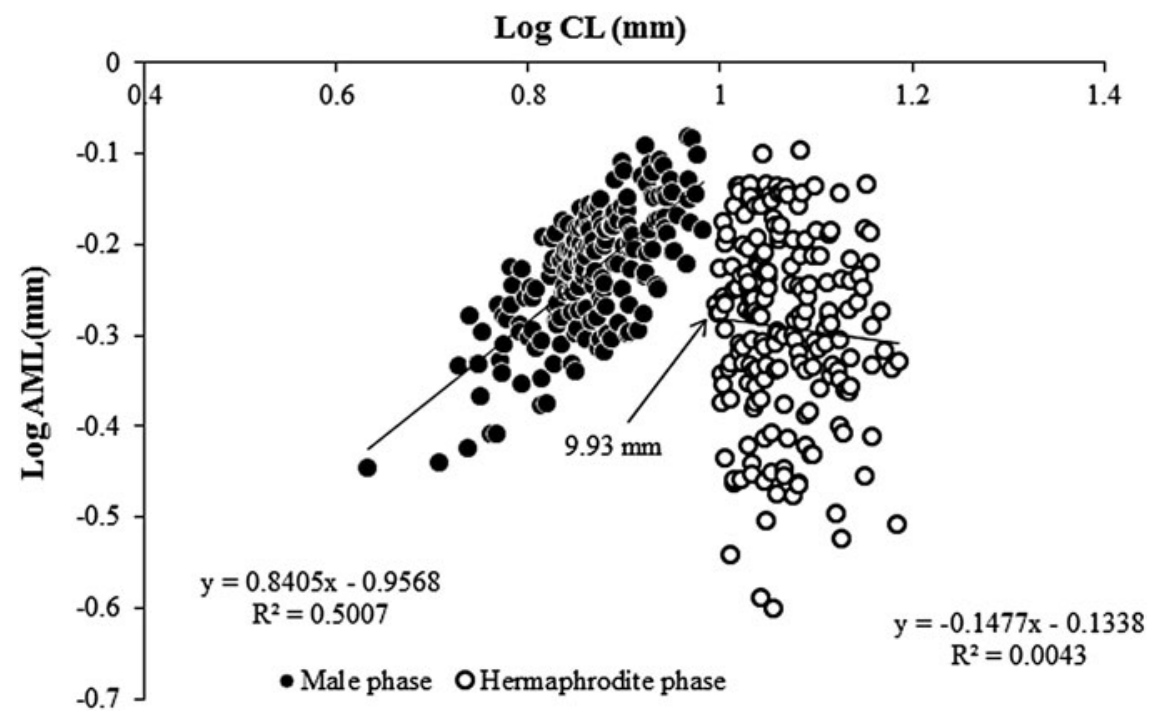

Fig. 5. Exhippolysmata oplophoroides (Holthuis, 1948). Estimated size at the change from the male to the hermaphrodite phase. The estimated size refers to the smallest individual after the inflection point of the phase equations for the male and hermaphrodite phases.

growth rate, mortality and size at the sex change in both regions. Different conditions of temperature and photoperiod had an effect on the sex change of $L$. wurdemanni under laboratory experiments (Bauer, 2002; Baldwin \& Bauer, 2003). Besides environmental conditions, social interactions in the population also may have a great influence on the size of sex change (Charnov et al., 1978; Baeza \& Bauer, 2004).

Both the male and hermaphrodite phases exhibited positive allometric growth in the length of second abdominal pleura. In caridean females, increase in the relative size of the first three abdominal pleura is an adaptation for brooding embryos, so an increase in the growth of this structure is one of the factors related to reproductive success in the hermaphrodite phase (Bauer, 2004). Thus, morphological preparation for the incubation of embryos during the female (simultaneous hermaphrodite) phase begins during the male phase.

Negative allometric growth was found in relation to the first pereopod length in the male and hermaphrodite phases.
However, the second pereopod showed negative allometric growth in the male phase followed by positive allometric growth in the hermaphrodite phase. The first two pereopods in carideans are chelate; they are fundamental in activities such as food searching and handling, defence, territorial disputes and grooming (Bauer, 2004). Grooming behaviour reduces debris fouling on the body surface and thus prevents sensory and locomotion disabilities (Bauer, 1978). The positive allometry observed in the second pereopod, the grooming appendage in hippolytid carideans, is also an advantage in embryo incubation. In females with embryos, the chelae of the second pereopods are used for cleaning the mass of embryos, removing sediment and unfertilized eggs and thereby preventing bacterial growth in fertilized eggs (Bauer, 2004). An increase in the size of this structure in the hermaphrodite phase, besides being an advantage in the care of embryos, might also improve food collection, especially in a phase with high energy demand for embryo production.

Table 3. Exhippolysmata oplophoroides (Holthuis, 1948).

\begin{tabular}{|c|c|c|c|c|c|c|c|c|}
\hline Relationship & Phase & $N$ & $a$ & $b$ & $r^{2}$ & $T(b=1)$ & $P$ & Allometry \\
\hline \multirow[t]{2}{*}{ PL $v s \mathrm{CL}$} & MP & 199 & 0.409 & 1.090 & 0.856 & 2.830 & 0.001 & + \\
\hline & HP & 208 & 0.462 & 1.161 & 0.926 & $7 \cdot 318$ & 0.001 & + \\
\hline \multirow[t]{2}{*}{ FPL $v s \mathrm{CL}$} & MP & 199 & 0.034 & 0.897 & 0.756 & 2.845 & 0.001 & - \\
\hline & HP & 208 & 0.113 & 0.838 & 0.780 & 5.242 & 0.001 & - \\
\hline \multirow[t]{2}{*}{ SPL $v s \mathrm{CL}$} & MP & 197 & 0.194 & 0.896 & 0.771 & 2.979 & 0.001 & - \\
\hline & $\mathrm{HP}$ & 210 & 0.046 & 1.067 & 0.864 & 2.310 & 0.001 & + \\
\hline \multirow[t]{2}{*}{ AIL2 vs CL } & MP & 203 & 0.719 & 0.907 & 0.710 & 2.274 & 0.001 & - \\
\hline & HP & 204 & 0.943 & 1.186 & 0.715 & 3.532 & 0.001 & + \\
\hline \multirow[t]{2}{*}{$\mathrm{AIL}_{3} v s \mathrm{CL}$} & MP & 204 & 0.716 & 0.893 & 0.602 & 2.09 & 0.001 & - \\
\hline & $\mathrm{HP}$ & 203 & 0.873 & 1.096 & 0.707 & 1.920 & 0.001 & + \\
\hline \multirow[t]{2}{*}{$\mathrm{AIL}_{4} v s \mathrm{CL}$} & MP & 207 & 0.702 & 0.799 & 0.635 & 4.750 & 0.001 & - \\
\hline & $\mathrm{HP}$ & 200 & 0.881 & 1.056 & 0.658 & 1.018 & 0.001 & o \\
\hline \multirow[t]{2}{*}{$\mathrm{AIL}_{5}$ vs CL } & MP & 207 & 0.837 & 0.865 & 0.667 & 3.169 & 0.001 & - \\
\hline & HP & 200 & 1.034 & 1.110 & 0.633 & 1.692 & 0.001 & + \\
\hline \multirow[t]{2}{*}{$\mathrm{AML} v s \mathrm{CL}$} & MP & 204 & 0.956 & 0.840 & 0.500 & 2.689 & 0.001 & - \\
\hline & HP & 203 & 0.133 & -0.147 & 0.004 & 5.265 & 0.365 & - \\
\hline
\end{tabular}

Regression analysis of morphometric data.

AIL, length of appendix interna; AML, length of appendix masculine; CL, carapace length; FPL, length of first pereopod; PL, length of second pleuron; SPL, length of second pleopod; HP, simultaneous hermaphrodite phase; MP, Male phase, $+=$ positive allometry, $o=$ isometry, $-=$ negative allometry. 
Table 4. Growth parameters of Exhippolysmata oplophoroides (Holthuis, 1948) from Macaé/RJ (present study), Mar Virado and Ubatuba, on the north-eastern coast of São Paulo State, Brazil (Baeza et al., 2010).

\begin{tabular}{ccccccc}
\hline Location & $\begin{array}{l}\boldsymbol{L}_{\infty} \\
(\mathbf{m m})\end{array}$ & $\boldsymbol{k}$ & to & Longevity & Mortality & $\begin{array}{l}\text { Authority } \\
(\text { year })\end{array}$ \\
\hline Macaé/RJ & 19.89 & 0.17 & -0.24 & 2.19 & 0.07 & $\begin{array}{c}\text { Present } \\
\text { study }\end{array}$ \\
$\begin{array}{c}\text { Mar Virado } \\
\text { bay }\end{array}$ & 15.30 & 0.16 & -0.26 & 1.92 & 0.28 & $\begin{array}{c}\text { Baeza } \text { et al. } \\
(2010) \\
\text { Baeza } \text { et al. } \\
(2010)\end{array}$ \\
$\begin{array}{c}\text { Ubatuba } \\
\text { Bay }\end{array}$ & 16.60 & 0.08 & -2.53 & 4.92 & 0.13 & \\
\hline
\end{tabular}

The hermaphrodite phase showed a reduction in the appendix masculina with increased body size. In simultaneous hermaphrodite shrimps, a change from the male to the hermaphrodite phase is accompanied by changes in some structures, including a reduction in the size of this male appendix and the number of its spines (Bauer \& Holt, 1998; Bauer \& Newman, 2004). Previous studies on caridean shrimps have indicated that the appendix masculina is important in transferring spermatophores from the male to the female during copulation (Bauer, 1976; Berg \& Sandifer, 1984). However, Zhang \& Lin (2004) found that the second pleopods (with appendices masculinae) are not necessary for successful copulation in either phase in L. wurdemanni. Thus, the appendix may be a vestigial structure in the hermaphrodite phase without selective pressure to maintain it (Bauer, 2000). However, this does not explain its presence in the male phase, given the experiments of Zhang \& Lin.

The appendices internae of the second to fifth pleopods exhibited changes in the growth pattern (allometry) between the male and hermaphrodite phases. This pattern did not support the hypothesis that an enlarged appendices internae might be a substitute for the appendices masculinae, which are reduced or lost in the hermaphrodite phase. Pleopods of a segmental pair are linked by the cincinnuli of the appendices internae and help in the synchronized movement of pleopods during swimming (Bauer, 1976). One hypothesis for the positive allometry in this structure in the hermaphrodite phase is that it may provide an increased volume of the incubation chamber for embryos among pleopods, thus increasing the reproductive capacity.

Local environmental features such as lower temperatures and high primary productivity due to the Cabo Frio upwelling influence resulted in larger sizes, slower growth rates and lower mortality for E. oplophoroides when compared with this species in the Ubatuba/SP region. The high primary productivity in the study area may have also contributed to a sex ratio biased towards HPs, since it provides the increased food and energy needed to sustain embryo production. Thus, the environmental conditions associated with upwelling resulted in reproduction and growth more characteristic of higher latitudes.

\section{ACKNOWLEDGEMENTS}

Thanks are due to all members of the LABCAM, and to Dr Alexandre Azevedo and Dr Gustavo Sérgio Sancinetti for their help during fieldwork. We also thank the Universidade Federal do Rio de Janeiro/NUPEM for providing the infrastructure to carry out this work at Macaé, and the Instituto Brasileiro do Meio Ambiente e dos Recursos Naturais
Renováveis (IBAMA) for granting us permission to collect the shrimp (SISBIO N $\mathrm{N}^{\circ}$ 23012-1). This is Contribution No. 185 of the Laboratory of Crustacean Research (R.T. Bauer), University of Louisiana, Lafayette.

\section{FINANCIAL SUPPORT}

The authors are grateful for funding from the São Paulo Research Foundation - FAPESP (AR \#2009/54672-4 and Biota Temático 2010/50188-8 to RCC, and a scholarship \#2013/12136-4 to RAP, Conselho Nacional de Desenvolvimento Cientifico e Tecnológico - CNPq (Proc. \# 406006/2012-1 and Scholarship 1D \# 305919/2014-8 to RCC and Scholarship \#130837/2011-3 to JAFP).

\section{REFERENCES}

Baeza J.A. (2007a) Sex allocation in a simultaneously hermaphroditic marine shrimp. Evolution 61, 2360-2373.

Baeza J.A. (2007b) Male mating opportunities affect sex allocation in a protandric-simultaneous hermaphroditic shrimp. Behavioral Ecology and Sociobiology 61, 365-370.

Baeza J.A. (2009) Protandric simultaneous hermaphroditism is a conserved trait in Lysmata (Caridea: Lysmatidae): implications for the evolution of hermaphroditism in the genus. Smithsonian Contributions to the Marine Sciences 38, 95-110.

Baeza J.A. and Bauer R.T. (2004) Experimental test of socially mediated sex change in a protandric simultaneous hermaphrodite, the marine shrimp Lysmata wurdemanni (Caridea: Hippolytidae). Behavioral Ecology and Sociobiology 55, 544-550.

Baeza J.A., Braga A.A., López-greco L.S., Perez E., Negreiros-Fransozo M.L. and Fransozo A. (2010) Population dynamics, sex ratio and size at sex change in a protandric simultaneous hermaphrodite, the spiny shrimp Exhippolysmata oplophoroides. Marine Biology 157, 26432653.

Baldwin A.P. and Bauer R.T. (2003) Growth, survivorship, lifespan, and sex change in the hermaphroditic shrimp, Lysmata wurdemanni (Decapoda: Caridea: Hippolytidae). Marine Biology 143, 157-166.

Bauer R.T. (1976) Mating behavior and spermatophore transfer in the shrimp Heptacarpus pictus (Stimpson) (Decapoda: Caridea: Hippolytidae). Journal of Natural History 10, 415-440.

Bauer R.T. (1978) Antifouling adaptations of Caridean shrimps: cleaning of the antennal flagellum and general body grooming. Marine Biology $49,69-82$

Bauer R.T. (2000) Simultaneous hermaphroditism in caridean shrimps: a unique and puzzling sexual system in the Decapoda. Journal of Crustacean Biology, Special Number 2, 116-128.

Bauer R.T. (2002) Tests of hypotheses on the adaptive value of an extended male phase in the hermaphroditic shrimp Lysmata wurdemanni (Caridea: Hippolytidae). Biological Bulletin 203, 347-357.

Bauer R.T. (2004) Remarkable shrimps: adaptations and natural history of the carideans. Norman, OK: University of Oklahoma Press.

Bauer R.T. (2005) Costs of maleness on brood production in the shrimp Lysmata wurdemanni (Decapoda: Hippolytidae: Caridea), a protandric simultaneous hermaphrodite. Journal of the Marine Biological Society of the United Kingdom 85, 101-106.

Bauer R.T. (2006) Same sexual system but variable sociobiology: evolution of protandric simultaneous hermaphroditism in Lysmata shrimps. Integrative and Comparative Biology 46, 430-438. 
Bauer R.T. (2013) Adaptive modification of appendages for grooming (cleaning; antifouling) and reproduction in the Crustacea. In Thiel M. and Watling L. (eds) Functional morphology of Crustacea, Vol. 1. New York, NY: Oxford University Press, pp. 337-375.

Bauer R.T. and Holt G.J. (1998) Simultaneous hermaphroditism in the marine shrimp Lysmata wurdemanni (Caridea: Hippolytidae): an undescribed sexual system in the decapod Crustacea. Marine Biology 132, 223-235.

Bauer R.T. and Newman W.A. (2004) Protandric simultaneous hermaphroditism in the marine shrimp Lysmata californica (Caridea: Hippolytidae). Journal of Crustacean Biology 24, 131-139.

Berg A.B.V. and Sandifer P.A. (1984) Mating behavior of the grass shrimp Palaemonetes pugio Holthuis (Decapoda, Caridea). Journal of Crustacean Biology 3, 417-424.

Beverton R.J.H. and Holt S.J. (1959) A review of the lifespans and mortality rates of fish in nature and the relation to growth and other physiological characteristics. Ciba Foundation Colloquia on Ageing 5 $142-177$.

Braga A.A., López-Greco L.S. and Fransozo A. (2009) Morphological evidence for protandric simultaneous hermaphroditism in the caridean Exhippolysmata oplophoroides. Journal of Crustacean Biology 29, 34-41.

Cerrato R.M. (1990) Interpretable statistical tests for growth comparisons using parameters in the von Bertalanffy equation. Canadian Journal of Fisheries and Aquatic Sciences 47, 1416-1426.

Chacur M.M. and Negreiros-Fransozo M.L. (1998) Aspectos biológicos do camarão-espinho Exhippolysmata oplophoroides (Holthuis, 1948) (Crustacea, Caridea, Hippolytidae). Revista Brasileira de Biologia 59, $173-181$.

Charnov E.L. (1982) The theory of sex allocation. Princeton, NJ: Princeton University Press.

Charnov E.L., Gotshall D.W. and Robinson J.G. (1978) Sex ratio: adaptive response to population fluctuations in Pandalid shrimp. Science 200, 204-206.

Costa R.C., Fransozo A., Mantelatto F.L.M. and Castro R.H. (2000) Occurrence of shrimp species (Crustacea: Decapoda: Natantia: Penaeidea and Caridea) in Ubatuba Bay, Ubatuba, SP, Brazil Proceedings of the Biological Society of Washington 113, 776-781.

De Léo F.C. and Pires-Vanin A.M. (2006) Benthic megafauna communities under the influence of the South Atlantic Central Water intrusion onto the Brazilian SE shelf: a comparison between an upwelling and a non-upwelling ecosystem. Journal of Marine Systems 60, 268-284.

D'Incao F. and Fonseca D.B. (1999) Performance of the von Bertalanffy growth curve in penaeid shrimps: a critical approach. In von Vaupe Klein C. and Schram F.R. (eds). The biodiversity crisis and Crustacea. Proceedings of the Fourth International Crustacean Congress. Amsterdam, the Netherlands. Leiden: Crustacean Issues 12 Rotterdam: A. A. Balkema, pp. 733-749.

Fransozo V., Costa R.C., Bertini G. and Cobo V.J. (2005) Population biology of spine shrimp Exhippolysmata oplophoroides (Holthuis) (Caridea: Alpheoidea: Hippolytidae) in a subtropical region, São Paulo, Brasil. Revista Brasileira de Zoologia 22, 1078-1084.

Ghiselin M.T. (1969) The evolution of hermaphroditism among animals. Quarterly Review of Biology 44, 189-208.

Hardy I.C.W. (2002) Sex ratios: concepts and research methods. Cambridge: Cambridge University Press.

Laubenheimer H. and Rhyne A. (2008) Experimental confirmation of protandric simultaneous hermaphroditism in a Caridean shrimp outside of the genus Lysmata. Journal of the Marine Biological Association of the United Kingdom 88, 301-305.
Lika K. (2003) Life historical implications of allocation to growth versus reproduction in dynamic energy budgets. Bulletin of Mathematical Biology 65, 809-834.

Mann K.H. and Lazier J.R.N. (1996) Dynamics of marine ecosystems: biological-physical interactions in the oceans, 2nd edition. Oxford: Blackwell Science.

Negreiros-Fransozo M.L., Gonzales-Gordilho J.I. and Fransozo A (2002) First larval stage of Exhippolysmata oplophoroides (Holthuis, 1948) (Decapoda, Caridea, Hippolytidae) obtained in laboratory. Nauplius 10, 67-71

Odebrecht C. and Djurfeldt L. (1996) The role of near shore mixing on phytoplankton size structure off Cape Santa Marta Grande, southern Brazil (Spring 1989). Archive of Fishery and Marine Research 43, 217-230.

Onaga H., Fiedler G.C. and Baeza A. (2012) Protandric simultaneous hermaphroditism in Parhippolyte misticia (Clark, 1989) (Caridea: Hippolytidae): implications for the evolution of mixed sexual systems in shrimp. Journal of Crustacean Biology 32, 383-394.

Pantaleão J.A.F., Carvalho-Batista A., Fransozo A. and Costa R.C. (2016) The influence of upwelling on the diversity and distribution of marine shrimp (Penaeoidea and Caridea) in two tropical coastal areas of southeastern Brazil. Hydrobiologia 763, 381-395.

Pauly D. (1980) On the interrelationships between natural mortality, growth parameters, and mean environmental temperature in 175 fish stocks. ICES Journal of Marine Science 39, 175-192.

Sampedro M.P., Gonzáles-Gurriarán E., Freire J. and Muiño R. (1999) Morphometry and sexual maturity in the spider crab Maja squinado (Decapoda: Majidae) in Galicia, Spain. Journal of Crustacean Biology 19, $578-592$

Schaffer W. (1983) The application of optimal control theory to the general life history problem. American Naturalist 121, 418-431.

Silva E.R., Sancinetti G.S., Fransozo A., Azevedo A. and Costa R.C. (2014) Biodiversity, distribution and abundance of shrimps Penaeoidea and Caridea communities in a region the vicinity of upwelling in Southeastern of Brazil. Nauplius 22, 1-11.

Sokal R.R. and Rohlf F.J. (1995) Biometry, 3rd edition. New York, NY: W. H. Freeman and Company.

Von Bertalanffy L. (1938) A quantitative theory of organic growth Human Biology 10, 181-213.

Warner R.R. (1975) The adaptive significance of sequential hermaphroditism in animals. American Naturalist 109, 61-82.

Wickler W. and Seibt U. (1981) Monogamy in Crustacea and man. Zeitschrift für Tierpsychologie 57, 215-234.

Zar J.H. (1996) Biostatistical analysis. Upper Saddle River, NJ: Prentice Hall.

and

Zhang D. and Lin J. (2004) Fertilization success without anterior pleopods in Lysmata wurdemanni (Decapoda: Caridea), a protandric simultaneous hermaphrodite. Journal of Crustacean Biology 24, 470-473.

\section{Correspondence should be addressed to:}

R.C. Costa

Laboratory of Biology of Marine and Freshwater Shrimp (LABCAM), Department of Biological Sciences, School of Sciences, University of Sao Paulo State (UNESP), Av. Eng. Luiz Edmundo Corrijo Coube, 14-01, 17033-360 Bauru, SP, Brasil

email: rccosta@fc.unesp.br 